\title{
Optimising Mechanical Properties of Hot Forged Nickel Superalloy 625 Components
}

\author{
Nthambe Singo, ${ }^{1, \text { a) }}$ John Coles, ${ }^{\text {b) }}$ Malgorzata Rosochowska, ${ }^{1, c)}$ \\ Himanshu Lalvani, ${ }^{1, \text { d) }}$ Jose Hernandez ${ }^{2, \text { e) }}$ and William Ion ${ }^{1,2, \text { f) }}$
}

\author{
${ }^{1}$ University of Strathclyde; Advanced Forming Research Centre (AFRC), Glasgow, Scotland UK \\ ${ }^{2}$ University of Strathclyde; Design, Manufacture \& Engineering Management (DMEM), Glasgow, Scotland UK \\ ${ }^{a)}$ Corresponding author: nthambes@gmail.com \\ b)johncoles@talktalk.net; ${ }^{c)}$ m.rosochowska@strath.ac.uk; ${ }^{\text {d) }}$ himanshu.lalvani@strath.ac.uk; \\ e)jose.hernandez@strath.ac.uk; f) w.j.ion@strath.ac.uk
}

\begin{abstract}
Hot forging and subsequent heat treatment were resulting in substandard mechanical properties of nickel superalloy, Alloy 625, components. The low strength was found to be due to inadequate deformation during forging, excessive grain growth and precipitation of carbides during subsequent heat treatment. Experimentation in a drop forging company and heat treatment facility led to the establishment of optimal parameters to minimise grain size and mitigate the adverse effects of carbide precipitation, leading to successful fulfilment of mechanical property specifications. This was achieved by reducing the number of operations, maximising the extent of deformation by changing the slug dimensions and its orientation in the die, and minimising the time of exposure to elevated temperatures in both the forging and subsequent heat treatment processes to avoid grain growth.
\end{abstract}

\section{INTRODUCTION}

Alloy 625 is a solid solution strengthened nickel-based superalloy with good fabricability, high strength at elevated temperature and superior corrosion resistance in a variety of environments. Its inherent high strength is a result of the stiffening effect of molybdenum and niobium on its nickel-chromium matrix and it does not require a precipitation hardening heat treatment [1].

Whilst most alloys are generally more formable at hot working temperatures, Alloy 625 retains high strength at high temperatures. This therefore minimises its formability even at hot working temperatures. This is overcome by using forging equipment of appropriate strength. Mechanical properties of the forged material depend on thermomechanical processing. When cold forged, its strength is significantly increased by work hardening due to deformation. When hot forged, however, exposure to elevated temperatures allows for recrystallization to occur and the resultant strength is lower than can be achieved with cold forging.

A post-forge annealing heat treatment is often applied, as in the case of the component used in this study, to ensure maximum corrosion resistance in service. This treatment may further lower the achievable strength of hot forged Alloy 625 and introduce a risk of precipitation of detrimental carbides along the grain boundaries. The type of the carbides formed depends on temperature and exposure time; $\mathrm{NbC}$ carbide in the form of thin boundary films and blocky $\mathrm{Cr}_{6} \mathrm{C}, \mathrm{Mo}_{6} \mathrm{C}$ and $\mathrm{Ni}_{6} \mathrm{C}$ carbides are formed in the temperature range $871-1038^{\circ} \mathrm{C}$ while $\mathrm{Cr}_{23} \mathrm{C}_{6}$ is formed in the $704-871^{\circ} \mathrm{C}$ range [2]. These carbides tend to precipitate preferentially at grain boundaries and if they form continuous networks along the boundaries, they have an embrittling effect and retard corrosion resistance. Most nickel based superalloys alloys tend to have primary carbides in the microstructure as a result of solidification reactions during casting [3] and these carbides are usually rich in nickel, niobium and molybdenum [1]. However, these carbides can be broken up in subsequent hot working operations, thus lessening their negative effects. 
In this study, early production attempts yielded components that failed to meet the specified yield and tensile strength values of 414 and $827 \mathrm{MPa}$, respectively. Further, the microstructures of these early components showed evidence of continuous networks of grain boundary precipitates. These precipitates could be dissolved in the postforge solution anneal, however, the temperatures at which solution would be optimal could cause grain growth and a consequent loss of strength. These conflicting effects created a challenge in satisfying all of the specified requirements.

The aim of the work described in this paper was to develop a consistent method of manufacture for Alloy 625 to produce forged components with mechanical properties that conformed to specifications and were free of detrimental precipitates.

\section{EXPERIMENTAL PROCEDURE}

The experimental procedure involved an initial review and analysis of the current forging and heat treatment practices. The original method of producing the selected Alloy 625 component consisted of the operations shown schematically in Fig. 1. Prior to forging on a $42 \mathrm{~kJ}$ pneumatic hammer, Ø44.5 x $90 \mathrm{~mm}$ cylindrical slugs weighing $1,1 \mathrm{~kg}$ were preheated at $1070^{\circ} \mathrm{C}$ for 20 minutes. Forging was carried out in three-impression dies - moulder, prefinisher and finisher, with reheating of the material between each die stage. The dies were heated to $240^{\circ} \mathrm{C}$ and a water solution of graphite was used as a lubricant. The slugs were laid horizontally in the first impression and several light blows were delivered to consecutively fill each of the three impressions. Partly forged components were clipped (removal of the flash) twice - an interim clip after pre-finishing, and a final clip after the final finishing operation. After final clipping, fully forged components were dropped into a container and allowed to cool in ambient air.

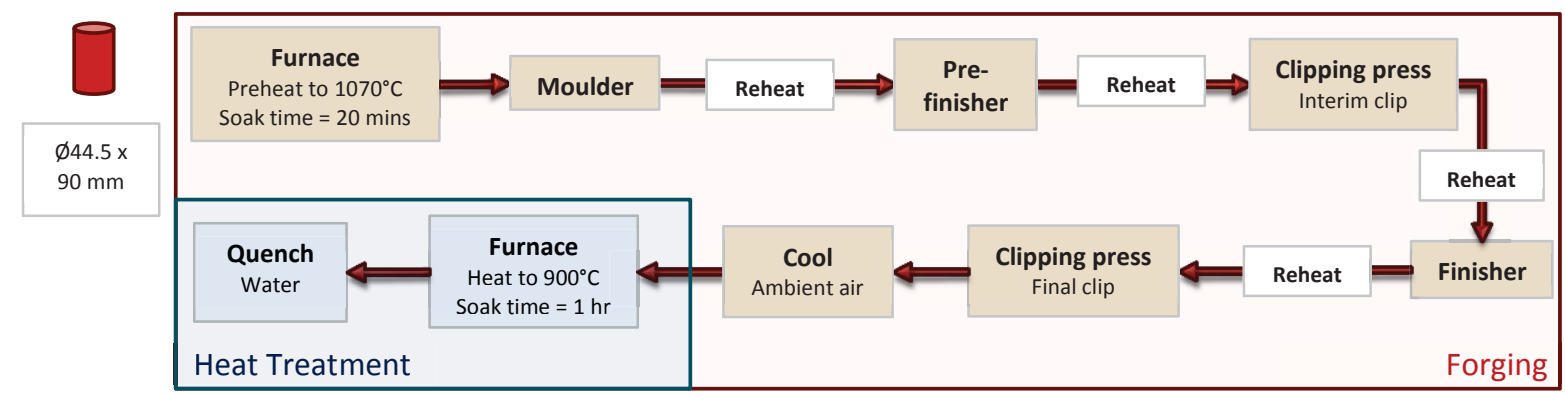

FIGURE 1. Schematic of original production route of forged components, showing forging and heat treatment operations

The post-forge heat treatment, carried out by a subcontractor, consisted of placing components in a preheated furnace, allowing them to rise up to the treatment temperature of $900{ }^{\circ} \mathrm{C}$ with the furnace, and soaking the components for 1 hour. Thereafter, components were removed from the furnace and quenched, within 5 seconds, into a water bath.

Metallographic examination and tensile testing were used to interrogate the hot forging and heat treatment processes to determine the factors contributing to loss of strength and initiation of carbide precipitation. Microstructure analysis of as-received material revealed the presence of carbides prior to forging. However, microstructure images obtained after the forging operation were free of carbides, suggesting that those carbides present in the as-received material dissolved during preheating. Figure 2 shows microstructures of as-received material and forged material. This figure also shows a substantial growth of grains. The microstructures of forged components are shown in Fig. 3. A thin film of carbides at the grain boundaries is evident at high magnification as shown in Fig. 3b. Energy dispersive X-ray (EDX) chemical analysis indicates the presence of carbide precipitates rich in nickel, niobium, molybdenum and chromium. According to work described in [3] the grain boundary carbides precipitated in Alloy 625 during heat treatment are primarily of $\mathrm{M}_{23} \mathrm{C}_{6}$ and $\mathrm{M}_{6} \mathrm{C}$ type.

Review of the production route, process parameters and results of mechanical testing and metallographic examination indicated that the likely causes of failure to achieve specified mechanical properties in Alloy 625 forged components were:

- insufficient material deformation during forging,

- grain growth as a result of over-exposure to elevated temperatures, 
- and inappropriate heat treatment temperature and time.

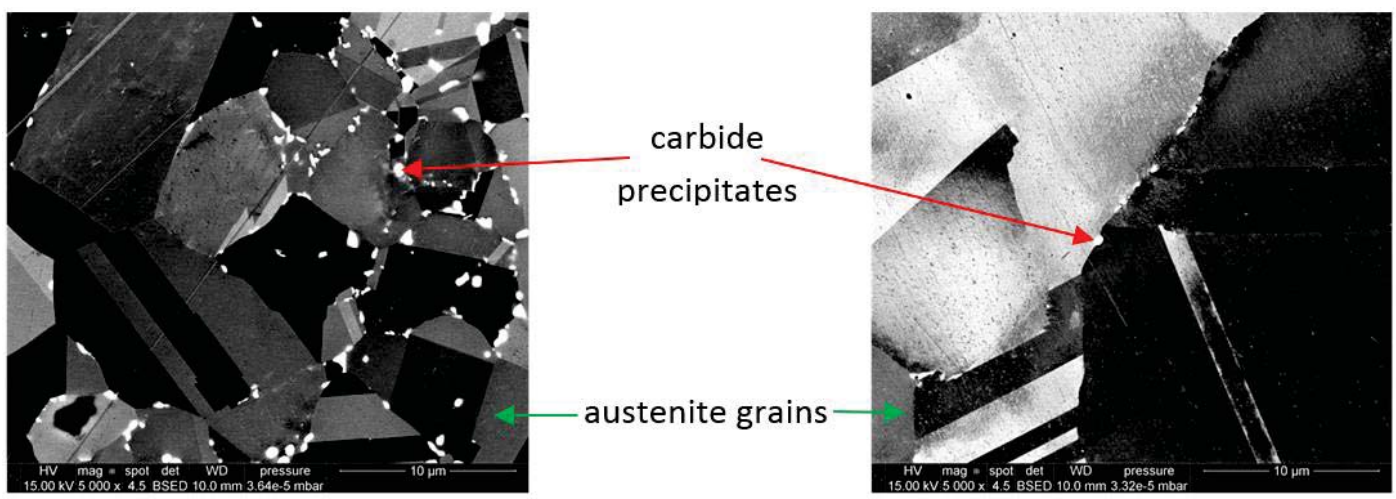

(a)

(b)

FIGURE 2. Microstructures of (a) as-received and (b) forged material, both at 5000x magnification

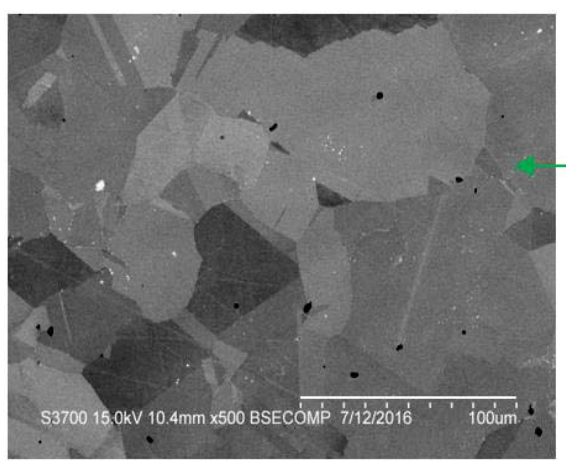

(a)

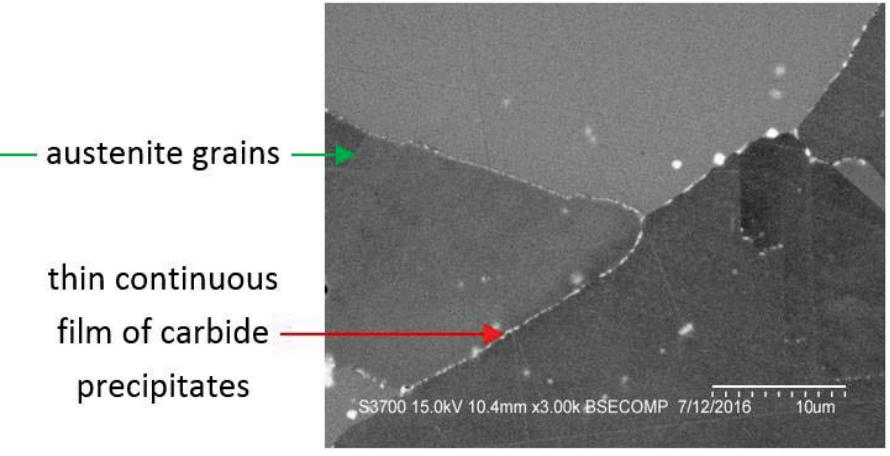

(b)

FIGURE 3. Microstructures of forged components forged at (a) 500x and (b) 3000x magnification, showing a thin film of continuous carbide precipitation at the grain boundaries

Based on the findings of the initial review, a series of forging trials was designed and carried out to establish the optimal manufacturing route to yield maximum strength in the produced components. Experimentation and redesign of the production process focused on tailoring the microstructure by refining the grain size, optimising grain flow, maximising deformation, as well as eliminating or constricting carbide precipitates to avoid formation of continuous networks at grain boundaries. The redesign consisted of:

- modification of the billet preheating practice and reduction of the number of operations to avoid overexposure to high temperatures,

- changing of the billet size and orientation in the die to promote more deformation,

- upsetting of the billet in the die to improve grain flow,

- and quenching of components immediately after forging to arrest grain growth and to avoid slow cooling through the temperature range where carbide precipitation prevails.

\section{RESULTS}

Forging trials designed to incorporate a combination of the changes described in the previous section and detailed testing of forged components led to development of a new production route which produced components that conformed to specifications. The new route is shown schematically in Fig. 4. The size of slugs was changed from $\varnothing 44.5 \times 90 \mathrm{~mm}(1.1 \mathrm{~kg})$ to $\varnothing 35 \times 94 \mathrm{~mm}(0.8 \mathrm{~kg})$, i.e. narrower, taller and lighter. The slugs were placed 
vertically over the first die impression, so that the first forging blows caused upsetting of the slugs, allowing for more deformation in forged components. Stored energy of deformation drives recrystallization and therefore results in a finer grained microstructure. A post-forge water quench was introduced to the production route. The main process modification was a reduced number of operations, which reduced the number of necessary reheats and consequently the exposure time to elevated temperatures during forging. The duration of the soak time in the postforge heat treatment was also reduced to eliminate the risk of precipitation of continuous network of carbides at the grain boundaries.

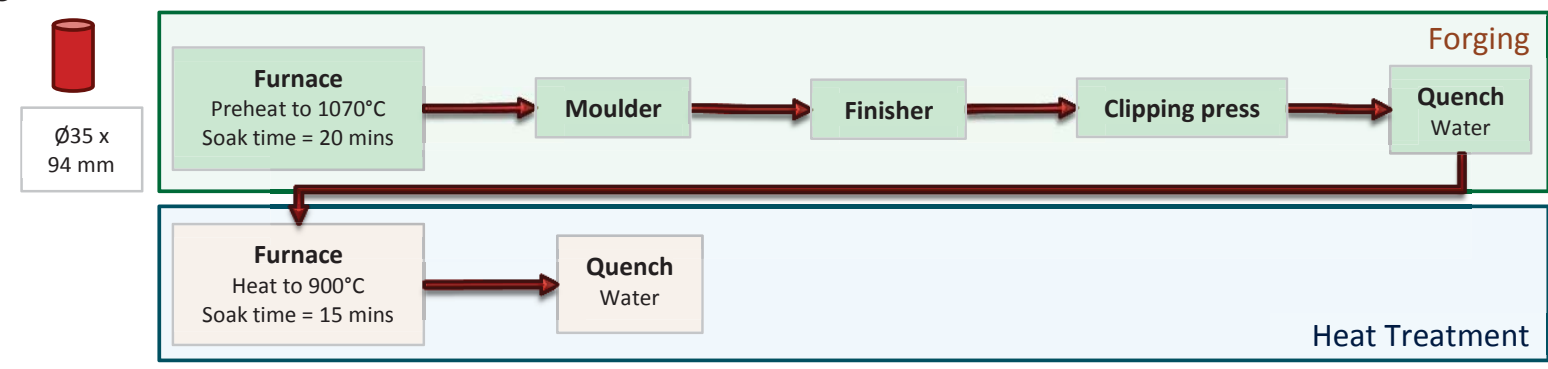

FIGURE 4. Schematic of optimised production route of forged components showing forging and heat treatment operations

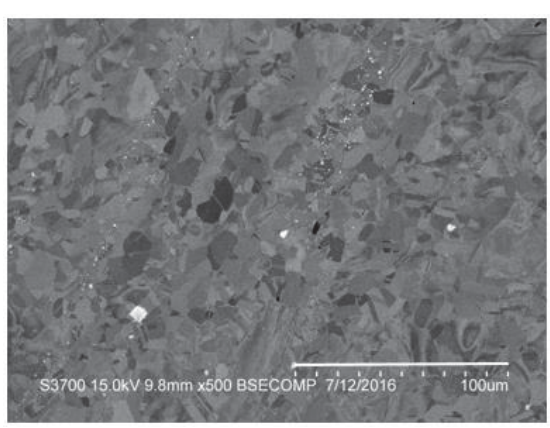

(a)

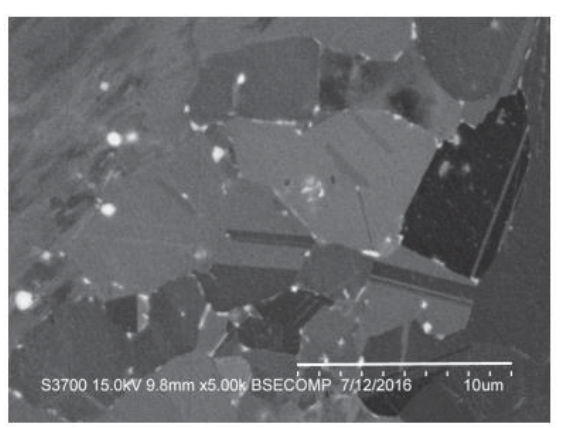

(b)

FIGURE 5. Microstructure of a component forged using the optimised production route at (a) 500x and (b) 5000x magnification; showing discontinuous carbides

While the resultant microstructure is not completely free of carbides, as shown in Fig. 5, their amount and distribution are of a preferable nature. Because they are not in continuous networks along grain boundaries, their negative effects are mitigated. Reducing exposure to high temperature in both forging and heat treatment resulted in a much finer grain size, as aimed. A comparison of the microstructure of earlier components and those produced using the optimised route is shown in Fig. 6. The benefits obtained from changing the dimensions and orientation of the slug and reducing high temperature exposure are shown in Table 1, through results of mechanical testing.

TABLE 1. Forging reduction ratio and mechanical test results showing difference in properties between horizontal (original) and vertical (optimized) placement of forging slug over the die impression

\begin{tabular}{lccc}
\hline & Original route & Optimised route & Difference \\
\hline Forging reduction ratio & $3: 1$ & $3.24: 1$ & $8 \%$ \\
\hline Yield strength & $373 \mathrm{MPa}$ & $510 \mathrm{MPa}$ & $36.7 \%$ \\
Tensile strength & $815 \mathrm{MPa}$ & $896 \mathrm{MPa}$ & $10 \%$ \\
Elongation & $60.2 \%$ & $48.0 \%$ & $20.2 \%$ \\
Hardness & $15 \mathrm{HRC}$ & $21 \mathrm{HRC}$ & $40 \%$ \\
\hline
\end{tabular}




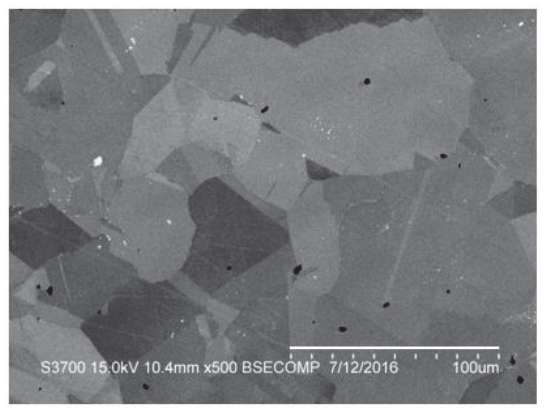

(a)

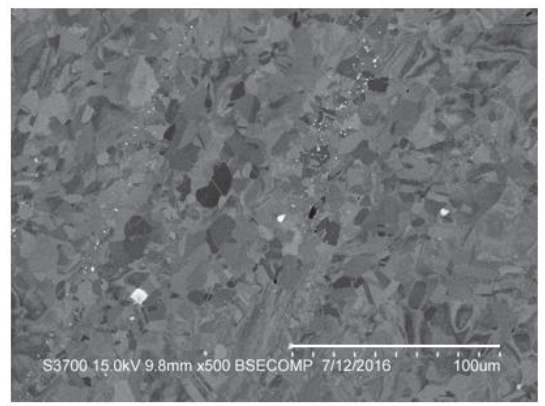

(b)

FIGURE 6. Comparison of microstructure of a component forged using the (a) original and (b) optimised production routes

\section{DISCUSSION}

Because mechanical properties of this grade of superalloy are dependent on thermomechanical processing, the forging process has a significant effect on the final strength of the components. The grain structure, which is a major determinant of properties, is determined by the temperature regime and strain imparted by the forging process.

\section{Temperature Regime}

\section{Forging}

The standard forging procedure in a hot drop forge includes preheating of slugs to above their recrystallization temperature $\left(T_{R}\right)$. Above this temperature, dislocations created by plastic deformation rearrange themselves into a polygonised structure, relieving internal stresses. New, refined, equiaxed grains nucleate at the cell boundaries of the polygonised structure, reducing the dislocation density and therefore increasing the material's ductility [4]. The material regains its ability to flow, allowing for further forging of the material without fracture. However, overexposure to temperatures above $T_{R}$ may cause grain growth. Hence, the slug preheating practice in this study was modified to reduce high temperature exposure. The initial production route involved several reheats of slugs/partly forged parts. This was necessary due to the chilling effect of the die which resulted from using several light blows and consequently, prolonged contact with the much cooler dies. The application of two full capacity blows of the hammer, related to the altered size and positioning of the slug, enabled reduction of the number of forging operations to just two - moulder and finisher - and to elimination of reheating. In the original production route, the final reheat was followed by immediate clipping, with no further working of the parts. The material had no opportunity to recover strength after the final reheat. The optimised production route, by introducing upsetting of the slug and eliminating reheats, maximised the amount of strength developed by the material during forging.

\section{Post-forge Quenching}

Quenching of the parts immediately after forging was introduced. This would have the dual effect of avoiding slow cooling through the carbide-forming temperature regions and arresting grain growth, thereby preserving strength developed by the material during forging. Quenching was not found to have a noticeable effect on the mechanical properties of as-forged material.

\section{Heat treatment}

Forged Alloy 625 components were found to be subjected to over-annealing at the subcontractor's. The initial temperature $\left(900^{\circ} \mathrm{C}\right)$ and time $(1$ hour) employed by the subcontractor fall within the range where carbide precipitation is prevalent, as evidenced by the microstructure obtained in Fig. 3. According to the TTT diagram for carbides forming in Alloy 625 [3], the precipitation of $\mathrm{MC}$ and $\mathrm{M}_{6} \mathrm{C}$ types of carbides starts after soaking at this temperature for about $30-40$ minutes. At that temperature, avoiding carbide formation would require a shortened 
annealing time. Avoiding the carbide forming temperature range of $700-1040{ }^{\circ} \mathrm{C}$ altogether would be have been ideal, however, soaking the samples below $700{ }^{\circ} \mathrm{C}$ would not qualify as annealing, while soaking above $1040{ }^{\circ} \mathrm{C}$ might lead to grain growth and a resultant loss of strength. A compromise of soaking the components at $900{ }^{\circ} \mathrm{C}$ for 15 minutes was reached. This allowed for the dissolution of elements, from which this solid solution strengthening alloy derives its strength, and avoided excessive grain growth as shown in Fig. 5. The figure also shows that the microstructure was not completely carbide-free, nevertheless, the amount and distribution of carbides is not deemed detrimental.

\section{Strain Imparted by Forging}

Experimentation in this study included changing of the billet dimensions and orientation in the die to promote more deformation. Narrower, taller slugs were placed upright in the die instead of horizontally. This optimized the grain flow and allowed for more extensive deformation, resulting in more superior mechanical properties in asforged components. The change in slug dimensions also had the collateral effect of a $27 \%$ material saving per forged component.

Maximizing the strain imparted by forging not only improves the mechanical properties of as-forged components, but it also has significant impact on the final grain size that can be achieved after heat treatment. The final grain size of annealed material is determined by the degree of prior deformation, time at temperature, annealing temperature, heating time and insoluble impurities; with degree of deformation being the most influential of these factors. More extensively deformed material favours nucleation of new, equiaxed grains and decreases the final grain size [5].

\section{CONCLUSIONS}

The modification of production parameters resulted in optimised grain flow and size, and consequently a significant increase in the tensile strength of as-forged samples. Maximising the extent of deformation during forging and minimising the time of exposure to elevated temperatures during both the forging and subsequent heat treatment processes mitigated the effects of carbide precipitates and resulted in improved mechanical properties of Alloy 625 components.

From the findings of this study, the following guidelines can be recommended for the hot drop forging of Alloy 625 components:

- Ideally, the temperature range $700-1040{ }^{\circ} \mathrm{C}$ is to be avoided during both forging and heat treatment to prevent carbide precipitation.

- If the aforementioned temperature range cannot be avoided, the pre-heating soak times during forging and heat treatment should be minimised. This will avoid carbide precipitation as well as retain material strength imparted by the forging process.

- Heat treatment between 1070 and $1080{ }^{\circ} \mathrm{C}$ is recommended. If a temperature of $1070-1080{ }^{\circ} \mathrm{C}$ is found to be significantly detrimental to the mechanical properties then a temperature of $900{ }^{\circ} \mathrm{C}$ can be employed, however, the soak time is to be kept as short as possible.

\section{REFERENCES}

1. Inconel Alloy 625, Data Sheet, Special Materials. http://www.specialmetals.com/assets/smc/documents/alloys/inconel/inconel-alloy-625.pdf, Accessed on 21/06/2016

2. S. Floreen, G.E. Fuchs and W.J. Yang, "The Metallurgy of Alloy 625" in Superalloys 718, 625, 706 and Various Derivatives, edited by E.A. Loria (The Minerals, Metals \& Materials Society, Huntington, 1994), pp. 13-37

3. M. Sundararaman et al., "Carbide Precipitation in Nickel Base Superalloys 718 And 625 and Their Effect on Mechanical Properties" in Superalloys 718, 625, 706 and Various Derivatives, edited by E.A. Loria (The Minerals, Metals \& Materials Society, New York, 1997), pp. 367-378

4. D. R. Askeland, P. P. Fulay and W. J. Wright, The Science and Engineering of Materials 6th Edition, (Cengage Learning, Stamford USA, 2011), pp. 308-313

5. S.H. Avner, Introduction to Physical Metallurgy, (McGraw-Hill Inc., 1964, USA), pp 100-109 